\title{
A utilização do Plano de Desenvolvimento Individual por professores em Minas Gerais
}

\author{
The use of the Individual Development Plan by teachers in Minas Gerais \\ El uso del Plan de Desarrollo Individual por parte de los maestros en Minas \\ Gerais
}

\author{
Bruna Cristina da Silva Hudson \\ Psicóloga, Mestra em Educação, Conhecimento e Inclusão Social pela Universidade Federal de Minas \\ Gerais, Belo Horizonte, Minas Gerais, Brasil. \\ brunacris.huds93@gmail.com \\ ORCID - https://orcid.org/0000-0001-5335-0440
}

Adriana Araújo Pereira Borges

Professora doutora na Universidade Federal de Minas Gerais, Belo Horizonte, Minas Gerais, Brasil. adriana.borges@terra.com.br

ORCID - https://orcid.org/0000-0003-0493-0099

Recebido em 1 julho 2020

Aprovado em 10 de setembro de 2020

Publicado em 26 de outubro de 2020

\section{RESUMO}

O Plano de Desenvolvimento Individual (PDI), ou Plano de Ensino Individualizado (PEI), é definido pela Secretaria de Estado da Educação de Minas Gerais (SEEMG) como um recurso obrigatório no processo de inclusão escolar dos alunos da Educação Especial, nas classes comuns de ensino. Apesar da importância do PDI e da obrigatoriedade de sua utilização nas escolas estaduais, é necessário compreender qual a percepção dos professores acerca de sua aplicação. Para tanto, foi realizada uma pesquisa tipo survey, com o uso de questionários que foram respondidos de forma online pelo público formado por professores regentes, professores de apoio, professores do Atendimento Educacional Especializado (AEE), diretores e especialistas da rede estadual de educação. Foram recebidas 1.286 respostas. Os resultados indicaram a necessidade de capacitação dos docentes para a utilização do PDI e do melhor preparo do especialista para conduzir o preenchimento e prestar assistência aos professores. Além disso, foram indicados no documento os pontos considerados confusos, complexos ou mal interpretados pelos profissionais e a necessidade de um estímulo para um trabalho colaborativo na execução da tarefa. A proposta curricular orientada pelo Projeto Político Pedagógico, a avaliação diagnóstica inicial do aluno, o planejamento pedagógico e a avaliação e correção de rumos foram os itens identificados como os mais problemáticos. Conclui-se que o PDI é um recurso importante para a promoção da acessibilidade curricular; no entanto, sua escrita e sua utilização requerem uma formação mais consistente por parte dos profissionais que atuam na escola, uma maior participação da família e de outros profissionais que acompanham a criança.

Palavras-chave: Plano de desenvolvimento individual; inclusão escolar; Educação Especial. 
http://dx.doi.org/10.5902/1984686X47967

\section{ABSTRACT}

The Individual Development Plan (PDI) or Individualized Education Plan (PEI) is defined by the Minas Gerais State Department of Education (SEEMG) as a mandatory resource in the school inclusion process of special education students in common teaching classes. Despite the importance of the PDI and the mandatory use of it in state schools, it is necessary to understand the perception of teachers about its application. For this, a survey-type research was carried out, through questionnaires that were answered online by the public formed by conducting teachers, support teachers, teachers from the Specialized Educational Service (AEE), directors and specialists from the state education network. Were received 1.286 responses. The results indicated the need for teacher training for the use of the PDI and the better preparation of the specialist to conduct the filling and provide assistance to teachers. In addition, it was identified in the document the points that were confusing, complex or misinterpreted by professionals and the need for a stimulus for collaborative work in the execution of the task. The curricular proposal according to the Political Pedagogical Project, the initial diagnostic evaluation of the student, the pedagogical planning and the assessment and correction of directions, were the items identified as most problematic. It is concluded that the PDI is an important resource for the promotion of curricular accessibility; however, the writing and the use requires more consistent training on the part of the professionals who work at the school, greater participation by the family and other professionals who accompany the child.

Keywords: Individual development plan; school inclusion; Special Education.

\section{RESUMEN}

El Plan de Desarrollo Individual (PDI) o el Plan de Educación Individualizado (PEI) está definido por el Departamento de Educación del Estado de Minas Gerais (SEEMG) como un recurso obligatorio en el proceso de inclusión escolar de estudiantes de educación especial en clases de enseñanza comunes. A pesar de la importancia del PDI y el uso obligatorio de este en las escuelas públicas, es necesario comprender la percepción de los maestros sobre su aplicación. Con este fin, se realizó una encuesta tipo survey, utilizando cuestionarios que fueron respondidos en línea por el público formado por maestros directores, maestros de apoyo, maestros del Servicio Educativo Especializado (AEE), directores y especialistas. Se recibieron 1.286 respuestas. Los resultados indicaron la necesidad de capacitación docente para el uso del PDI y la mejor preparación del especialista para llevar a cabo el llenado y brindar asistencia a los maestros. Además, los puntos identificados en el documento como confusos, complejos o mal interpretados por profesionales y la necesidad de un estímulo para el trabajo colaborativo en la ejecución de la tarea. La propuesta curricular según el Proyecto Político Pedagógico, la evaluación diagnóstica inicial del alumno, la planificación pedagógica y la evaluación y corrección de direcciones, fueron los ítems identificados como los más problemáticos. Se concluye que el PDI es un recurso importante para la promoción de la accesibilidad curricular; sin embargo, su escritura y su uso requiere una formación más consistente por parte de los profesionales que laboran en la escuela, una mayor participación de la familia y otros profesionales que acompañan al niño.

Palabras clave: Plan de desarrollo individual; inclusión escolar; Educación Especial. 
http://dx.doi.org/10.5902/1984686X47967

\section{Introdução}

A Educação Especial na perspectiva da Educação Inclusiva é hoje uma realidade nas escolas brasileiras. Dados do Censo da Educação Básica apontam o crescimento constante nas matrículas em escolas comuns do número de alunos com deficiência, com Transtornos Globais do Desenvolvimento (TGD) ou altas habilidade/superdotação (Público Alvo da Educação Especial ou PAEE). Em Minas Gerais, os alunos matriculados em escolas municipais ou estaduais, públicas ou privadas da Educação Básica correspondem a 4.364.668. Nesse universo, os alunos da Educação Especial totalizam 116.037 (2,6\%) matrículas nas classes comuns de ensino regular e $26.061(0,6 \%)$ estão matriculados em escolas exclusivamente especializadas e/ou em classes exclusivas de ensino. Alunos com Deficiência Intelectual constituem o grupo com maior número de matrículas nas classes comuns, correspondendo a 73\%, em seguida, estudantes diagnosticados com Autismo, com 15\%, estudantes com Deficiência Física representam 11\% e outros diagnósticos (INEP, 2019).

No entanto, os dados indicam que o número total de alunos PAEE matriculados nas classes comuns em escolas públicas e privadas tende a diminuir com os anos de escolarização, ou seja, existem mais alunos com deficiência no Ensino Fundamental do que no Ensino Médio. Enquanto em 2019 havia 83.829 matrículas de alunos PAEE no ensino Fundamental, no Ensino Médio existiam apenas 16.980, o que corresponde a apenas 20\% (INEP, 2019). Portanto, ainda existe uma espécie de "gargalo" que impede a chegada dos alunos com deficiência nos níveis mais altos de escolarização. Observa-se que o número de matrículas iniciais poderá continuar elevado nos próximos anos, mas a preocupação deve ser voltada para a permanência e a aprendizagem dos educandos nesse processo, garantindo que eles acompanhem toda a escolarização de forma satisfatória. A aprendizagem e a permanência são assuntos mais complexos que dependem de atitudes, tecnologias e instrumentos que promovam a equidade no ensino.

De acordo com o Censo Escolar de 2019, o número de escolas especializadas na rede estadual de ensino em MG era de 24 estabelecimentos, enquanto o PAEE estava presente nas classes comuns de 3.434 escolas. Em outras palavras, no total de 3.600 escolas estaduais, 95\% declararam-se como instituições que atendiam à Educação Especial em classes comuns. O número total de docentes contabilizados foi de 93.611 e o total de 73.097 professores ministraram aulas para os alunos PAEE (INEP, 2019). 
http://dx.doi.org/10.5902/1984686X47967

Para melhor administração do sistema escolar, o Estado conta com a Secretaria Estadual de Educação (SEE) e com 47 Superintendências Regionais de Ensino (SREs). As regiões do estado são bastante diferentes entre si e refletem a diversidade que existe no país. Nesse contexto tão amplo e que reúne diferentes populações, desde zonas rurais até regiões altamente industrializadas, é importante ter normas e diretrizes que organizem o sistema educacional estadual.

No caso de alunos que requerem Educação Especial, há a previsão do Atendimento Educacional Especializado (AEE) que é oferecido nas Salas de Recursos Multifuncionais (SRM). Os alunos contam com o auxílio do professor de AEE no contraturno. Esse professor auxilia na identificação de recursos de acessibilidade e tem a função de complementar (em caso de estudante com deficiência), ou suplementar (em caso de estudante com altas habilidades), a formação do aluno, disponibilizando serviços e desenvolvendo estratégias para a eliminação de barreiras que impeçam a plena participação social e a aprendizagem do estudante (MINAS GERAIS, 2018).

O professor regente atua nas salas de aula e é responsável pelo conteúdo das diversas disciplinas. Este deve executar um trabalho voltado para a diversidade e desenvolver um planejamento pedagógico para todos os alunos, inclusive o aluno da Educação Especial. Existe ainda a figura do professor de apoio à Comunicação, Linguagem e Tecnologias Assistivas, que auxilia o educando na comunicação, no acesso ao currículo adequando o material didático-pedagógico às suas necessidades, buscando promover a autonomia do estudante (MINAS GERAIS, 2018). Esse professor - mais conhecido como professor de apoio - trabalha diretamente com os alunos PAEE em sala de aula.

Já o especialista - também chamado de Supervisor Pedagógico ou Orientador Educacional - desempenha um papel fundamental no processo de inclusão, uma vez que ele é visto como um líder que direcionará a construção de um Plano de Desenvolvimento Individual (PDI) para o aluno. Ele fará a comunicação entre os profissionais para alcançar os objetivos e metas propostas. Ao especialista cabe a missão de sensibilizar e favorecer a reflexão dos colegas sobre a importância da construção desse instrumento de ensino (MINAS GERAIS, 2018).

O PDI é um recurso que deve ser utilizado de forma obrigatória. Desse modo,, todos os alunos PAEE matriculados nas escolas da rede estadual mineira devem possuir um Plano. Mesmo tratando-se de uma ferramenta importante, que pode facilitar a abordagem do professor e favorecer a inclusão dos estudantes, a hipótese da pesquisa é de que muitos 
http://dx.doi.org/10.5902/1984686X47967

professores ainda não a utilizam, seja por dificuldades de preenchimento, seja por não entenderem sua real importância.

Esse artigo tem por objetivo apresentar a percepção dos profissionais da educação do estado de Minas Gerais sobre o PDI instituído pela Secretaria Estadual de Educação, além de discutir sua utilização pelos professores das classes comuns de ensino com os alunos PAEE, discutindo pontos que podem ser aprimorados no documento.

\section{Plano de Desenvolvimento Individual}

Segundo Tannús-Valadão (2014), em países como os Estados Unidos, França, Suíça, Itália, Portugal, Alemanha, entre outros, o Planejamento Educacional Individualizado (PEI) tornou-se um dispositivo legal que acompanha o percurso escolar dos estudantes com deficiência nas instituições comuns de ensino. Embora a nomenclatura mude ${ }^{1}$, trata-se de um instrumento que tem estrutura e objetivos semelhantes: registrar os avanços dos alunos PAEE, bem como suas dificuldades.

No Brasil, não há um regulamento nacional que institua a obrigatoriedade na utilização do PDI, mas existem orientações sobre a importância da individualização do ensino. Documentos como a LDBEN (BRASIL, 1996) asseguram que os sistemas de ensino providenciem ajustes no contexto escolar para atender as necessidades dos estudantes. Os Parâmetros Curriculares Nacionais (BRASIL, 1998), as Diretrizes Nacionais para a Educação Especial na Educação Básica (BRASIL, 2001) e as Estratégias de Ensino para Educação de Alunos com Necessidades Educacionais Especiais (BRASIL, 2003) preveem a possibilidade de adaptar e flexibilizar conteúdos e versam sobre adequações curriculares individualizadas. Em 2000, o Projeto Escola Viva publicou o documento Garantindo o Acesso e Permanência de Todos os Alunos na Escola, salientando que um Plano de Ensino Individualizado pode ser elaborado por uma equipe multiprofissional e deve ser atualizado de forma processual de acordo com o percurso escolar do estudante (BRASIL, 2000).

Segundo Tannús-Valadão e Mendes (2018), foi a partir dos anos 2000 que o Brasil passou a adotar em leis estaduais e municipais a ideia da utilização de um Plano Educacional Individualizado. Essa proposta passou a reforçar a concepção de um planejamento de trabalho para a individualidade que, ao mesmo tempo, possa organizar e otimizar o percurso dos estudantes e guiar as práticas em sala de aula. A Lei Brasileira de Inclusão definiu no artigo 28, inciso V, a incumbência do poder público de assegurar aos alunos com deficiência "a adoção de medidas individualizadas e coletivas em ambientes 
que maximizem o desenvolvimento acadêmico e social dos estudantes com deficiência, favorecendo o acesso, a permanência, a participação e a aprendizagem em instituições de ensino" (BRASIL, 2015).

O PEI consiste em um "registro avaliativo escrito, formulado em equipe, que busca as respostas educativas mais adequadas para as necessidades específicas apresentadas em processos de escolarização de estudantes que exigem caminhos alternativos para sua aprendizagem" (GLAT; VIANNA; REDIG, 2012, p. 84). O documento deve ser periodicamente avaliado, revisado e deve considerar o aluno em um "patamar atual de habilidades, conhecimentos e desenvolvimento, idade cronológica, nível de escolarização já alcançado e objetivos educacionais desejados em curto, médio e longo prazos" (GLAT; VIANNA; REDIG, 2012, p. 84).

Apesar de os inúmeros planos individualizados apresentarem estruturas e formas diferentes, existem informações gerais que podem ser observadas na maioria deles, tais como: "nome, idade, quanto tempo está na escola, aprendizagens já consolidadas, dificuldades encontradas, objetivos para este aluno, metas e prazos, os recursos ou adaptações curriculares utilizadas e os profissionais envolvidos na elaboração do plano" (GLAT; VIANNA; REDIG, 2012, p. 85). Independentemente de sua estrutura formal, o PDI busca garantir a acessibilidade curricular ao aluno PAEE.

\section{O Plano de Desenvolvimento Individual utilizado nas escolas estaduais mineiras}

Como parte integrante do processo de ensino e aprendizagem do aluno, a escola deve assegurar a todos os estudantes as condições adequadas para garantir o acesso, a participação plena nas atividades escolares, de forma equânime, flexível e a disponibilidade dos recursos necessários. Em Minas Gerais, diante da inclusão de alunos da Educação Especial no ensino comum, existe a obrigatoriedade na utilização do PDI (MINAS GERAIS, 2018).

Conforme o quadro 1 a seguir, o PDI mineiro é composto de nove itens: 
http://dx.doi.org/10.5902/1984686X47967

Quadro 1 - Modelo do PDI da rede estadual de Minas Gerais- ano 2018

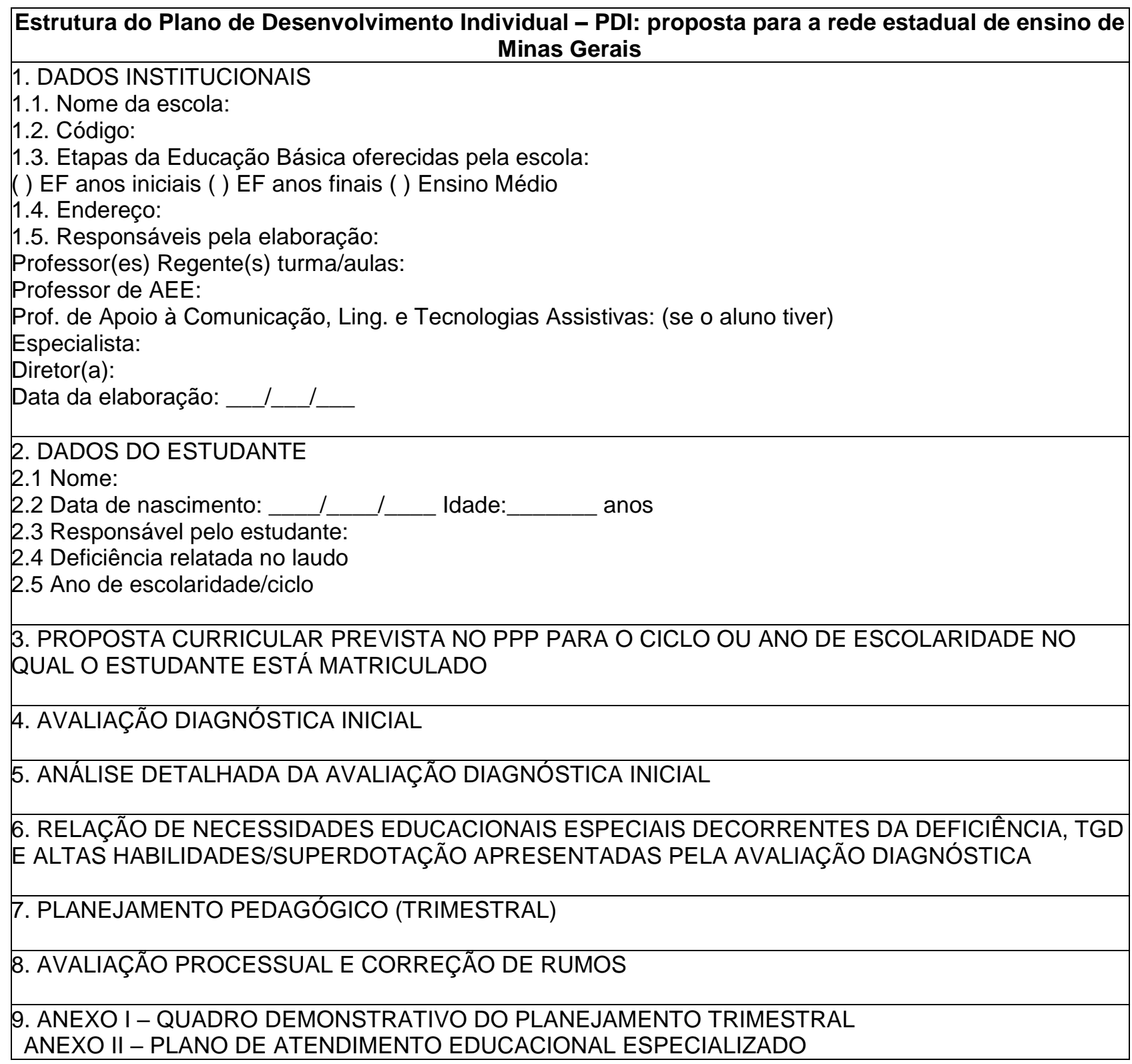

Fonte: Minas Gerais (2018, p. 5).

A Secretaria Estadual de Educação de Minas Gerais esclarece que o instrumento tem como finalidade a avaliação do percurso de aprendizagem do aluno de forma processual e descritiva. Tal instrumento constitui-se como um plano de aula mais estruturado, importante para a medição da aprendizagem dos alunos, comparando-os com eles mesmos, bem como para a avaliação da intervenção pedagógica (MINAS GERAIS, 2006).

Salienta-se que, embora a avaliação tenha um papel importante na sua elaboração, o Plano não se resume a isso, uma vez que se articula com o projeto pedagógico da escola, subsidiando a proposta educacional, além de abranger os planejamentos pedagógicos, os 
http://dx.doi.org/10.5902/1984686X47967

processos para implementação das atividades e a correção de rumos (MINAS GERAIS, 2014; 2018).

Ao utilizar o PDI, poderão ser traçadas melhores estratégias de intervenção, tendo em vista que no documento estarão dispostas as informações mais relevantes sobre o desenvolvimento do estudante $\mathrm{e}$ as potencialidades e dificuldades apresentadas no percurso educacional. Essa proposta, no Brasil, representa "uma importante estratégia para elaborar, implementar e avaliar adaptações curriculares que favoreçam a inserção de alunos com necessidades educacionais especiais em turmas regulares de ensino, norteando as ações pedagógicas dos professores" (VIANNA; SILVA; SIQUEIRA, 2011, p. 2.827). Além disso, "é uma alternativa promissora, na medida em que oferece parâmetros mais claros a serem atingidos com cada aluno, sem negar os objetivos gerais colocados pelas propostas curriculares" (GLAT; PLETSCH, 2013, p. 22). No entanto, é importante destacar que a obrigatoriedade da utilização do recurso pelos professores não garante a efetividade do uso do instrumento.

\section{Metodologia}

Foi realizada uma pesquisa quantitativa através do método survey. Babbie (2003) afirma que esse método enquadra-se em uma pesquisa em grande escala, que visa identificar a opinião dos participantes com o uso de questionários ou entrevistas. O método tem, ainda, o propósito de examinar uma amostra da população, caracterizando-se como um estudo de natureza exploratória. A amostra da pesquisa é não probabilística por acessibilidade ou conveniência, pois os dados foram analisados de acordo com o retorno dos questionários.

Constituíram-se como sujeitos da pesquisa professores regentes, professores de apoio, professores do $\mathrm{AEE}$, diretores e especialistas da rede estadual de educação básica que trabalham com alunos da Educação Especial incluídos em classes comuns, representando as 47 Superintendências Regionais de Ensino de Minas Gerais. Os sujeitos da pesquisa são os responsáveis pela elaboração do PDI, conforme citado no item 1.5 do quadro 1.

Durante o processo de elaboração do formulário da pesquisa, foi realizado um pré-teste que visou avaliar a eficácia do instrumento de pesquisa sem influenciar os resultados do trabalho, permitindo o refinamento do questionário para que atendesse aos objetivos propostos. Depois, iniciou-se a coleta dos dados oficiais, no período de 29/04/2019 a 25/05/2019, a partir de um questionário elaborado no 'Google Forms'. O convite foi enviado 
http://dx.doi.org/10.5902/1984686X47967

através de um e-mail institucional pela Diretoria de Educação Especial² da SEE para todas as regionais e instituições escolares, as quais o reencaminharam para o público-alvo.

Foi realizada uma análise estatística com o uso dos softwares SPSS e Microsoft Excel sobre as respostas de 1.286 participantes. Foram obtidas respostas de 44 de um total de 47 regionais. Dentre as que não participaram estão Itajubá, Patrocínio e Pirapora. A partir dos dados, foram realizadas associações entre questões levantadas sobre o uso do PDI e as possíveis dificuldades de preenchimento; a formação e a preparação dos profissionais para atuar com o público da Educação Especial; as reais demandas dos professores e as informações contidas no documento.

\section{Resultado}

\section{Público-alvo da pesquisa e formação profissional}

Os diretores formam o grupo com o maior número de respondentes, totalizando 38\%; em seguida, estão os especialistas, com $27 \%$, os professores de apoio, com $13 \%$, os professores do AEE, com $10 \%$, e os professores regentes, com $7 \%$.

Os diretores, apesar de incentivados a participar da construção do PDI pela cartilha orientadora da SEE/MG, não costumam assumir essa função que, em princípio, deveria ficar a cargo dos professores de apoio e dos regentes. Obteve-se pelo menos uma resposta de diretores em todas as SREs. Esse dado sugere que o questionário pode não ter sido encaminhado para o corpo docente da escola ou, caso tenha chegado aos profissionais, houve um desinteresse pela pesquisa ou pela temática. Pode sugerir, ainda, que o diretor da escola sentiu-se na responsabilidade de falar em nome de sua equipe. Chamou a atenção o baixo número de professores regentes respondentes, apenas 7\% da amostra, como mencionado. Essa baixa adesão pode indicar que os professores da escola comum não assumem, na prática, a responsabilidade didática pelos alunos com deficiência incluídos em suas turmas (GLAT; PLETSCH, 2012). Tannús-Valadão (2014) identificou em seus estudos, que o professor da sala de recursos era o mesmo responsável pelo preenchimento do PEI na maior parte das vezes, o que dificultava a relação do documento com o ensino da classe comum. Dentre os empecilhos que podem impedir o professor regente de executar essa tarefa estão o acúmulo de atividades, a dificuldade em trabalhar com a diversidade e até mesmo a isenção de responsabilidade, ao acreditar que a educação do aluno com deficiência é obrigação do professor de apoio ou do professor da Sala de Recursos. Além disso, o PEI não seria algo que as escolas e os professores estão habituados a trabalhar, pois esse recurso não faz parte da 
http://dx.doi.org/10.5902/1984686X47967

cultura escolar, carecendo de mais estímulos para seu uso e reconhecimento de sua importância (SIQUEIRA et al., 2013).

Do total de 1.286 respostas, $73 \%$ dos participantes afirmaram ter alguma formação, mas chama a atenção o fato de 352 (27\%) afirmarem não ter recebido nenhuma formação para atuar junto ao PAEE (Tabela 1).

Tabela 1 - Formação para atuar com o aluno PAEE

\begin{tabular}{lccc}
\hline & $\begin{array}{c}\text { Não faço e/ou não } \\
\text { tenho formação }\end{array}$ & Sim, tenho formação & $\begin{array}{c}\text { Sim, inclusive oferecidos } \\
\text { pela escola e pelo governo }\end{array}$ \\
\hline Diretor & 234 & 163 & 118 \\
\hline Professor de apoio & - & 144 & 36 \\
\hline Professor do AEE & - & 96 & 37 \\
\hline Professor regente & 41 & 42 & 11 \\
\hline Especialista & 77 & 203 & 84 \\
\hline Total & $\mathbf{3 5 2}$ & $\mathbf{6 4 8}$ & $\mathbf{2 8 6}$ \\
\hline
\end{tabular}

Fonte: Elaborada pelas autoras (2020).

Discutir acerca da formação é extremamente relevante, uma vez que diversas pesquisas apontam que a capacitação do profissional é fundamental para alcançar a qualidade no ensino. A formação continuada é necessária para que os docentes aprimorem suas práticas e conhecimentos. Na maioria das vezes, a formação inicial não é suficiente ou satisfatória para suprir a demanda apresentada pela Educação Especial. Alguns pesquisadores afirmam que o currículo de formação de professores não capacita os futuros docentes para realizarem adaptações necessárias para proporcionar um ensino de qualidade e que essa formação carece de uma estrutura dialógica, baseada em percursos formativos que evidenciem de forma mais proveitosa a articulação entre teoria com a prática (OLIVEIRA; MACHADO, 2013; REDIG; MASCARO; DUTRA, 2017).

Uma pergunta realizada no questionário era a respeito da capacitação dos profissionais para utilizar o PDI. Os dados representam as respostas de 1.254 participantes que conheciam o PDI e os que trabalhavam ou já haviam trabalhado com o aluno PAEE. Os outros 32 encerraram a participação por não conhecerem o instrumento e/ou nunca terem trabalhado com o aluno da Educação Especial. Os resultados apontaram que 39,1\% não receberam capacitação e uma amostra significativa de 60,8\% assinalou que foi capacitada. Porém, não é possível considerar apenas o resultado geral, tendo em vista as realidades diferentes em cada região do estado de Minas Gerais. Ao restringir os resultados conforme a regional, foi possível perceber que nenhuma SRE realizou a capacitação total dos seus docentes, pois os dados oscilaram em todas as regiões (Tabela 2). 
Tabela 2 - Sobre a capacitação para utilizar o PDI

\begin{tabular}{|l|c|c|c|}
\hline SRE & Sim & Não & Total \\
\hline Almenara & 13 & 5 & 18 \\
\hline Araçuaí & 9 & 3 & 12 \\
\hline Barbacena & 40 & 19 & 59 \\
\hline Campo Belo & 4 & 5 & 9 \\
\hline Carangola & 9 & 8 & 17 \\
\hline Caratinga & 13 & 3 & 16 \\
\hline Caxambu & 10 & 8 & 18 \\
\hline Conselheiro Lafaiete & 6 & 9 & 15 \\
\hline Coronel Fabriciano & 5 & 12 & 17 \\
\hline Curvelo & 10 & 2 & 12 \\
\hline Diamantina & 18 & 3 & 21 \\
\hline Divinópolis & 37 & 12 & 49 \\
\hline Governador Valadares & 15 & 17 & 32 \\
\hline Guanhães & 6 & 3 & 9 \\
\hline Ituiutaba & 6 & 5 & 11 \\
\hline Janaúba & 20 & 7 & 27 \\
\hline Januária & 15 & 9 & 24 \\
\hline Juiz De Fora & 21 & 5 & 26 \\
\hline Leopoldina & 10 & 8 & 18 \\
\hline Manhuaçu & 9 & 19 & 28 \\
\hline Metropolitana A & 21 & 19 & 40 \\
\hline Metropolitana B & 77 & 47 & 124 \\
\hline Metropolitana C & 13 & 10 & 23 \\
\hline Monte Carmelo & 14 & 8 & 22 \\
\hline Montes Claros & 15 & 10 & 25 \\
\hline Muriaé & 4 & 13 & 17 \\
\hline Nova Era & 37 & 35 & 72 \\
\hline Ouro Preto & 4 & 9 & 13 \\
\hline Pará De Minas & 10 & 6 & 16 \\
\hline Paracatu & 4 & 6 & 10 \\
\hline Passos & 7 & 7 & 14 \\
\hline Patos De Minas & 19 & 8 & 27 \\
\hline Poços De Caldas & 17 & 5 & 22 \\
\hline Ponte Nova & 25 & 22 & 47 \\
\hline Pouso Alegre & 30 & 15 & 45 \\
\hline São João Del Rei & 9 & 1 & 10 \\
\hline São Sebastião Do Paraíso & 25 & 9 & 34 \\
\hline Sete Lagoas & 30 & 16 & 46 \\
\hline Teófilo Otoni & 36 & 13 & 49 \\
\hline Ubá & 12 & 14 & 26 \\
\hline Uberaba & 12 & 13 & 25 \\
\hline Uberlândia & 18 & 15 & 33 \\
\hline Unaí & 1 & 5 \\
\hline Varginha & 49 & 71 \\
\hline TOTAL & & 1254 \\
\hline & & \\
\hline
\end{tabular}

Fonte: Elaborada pelas autoras (2020).

A rede estadual conta com espaços para a oferta de capacitação ao corpo docente, como os Centros de Apoio Pedagógico para Atendimento às Pessoas com Deficiência Visual (CAP) e os Centros de Capacitação de Profissionais da Educação e Atendimento às Pessoas com Surdez (CAS). No entanto, são necessárias ações mais sistematizadas para 
http://dx.doi.org/10.5902/1984686X47967

potencializar o processo de formação dos educadores. Glat, Vianna e Redig (2012) insistem na necessidade de promover nas escolas, situações de formação continuada que possibilitem ações colaborativas, além da troca de conhecimentos produzidos na universidade e os saberes docentes.

Segundo pesquisadores do campo da Educação Especial, os cursos deveriam promover debates para a criação de uma consciência crítica acerca da realidade do trabalho, oferecer fundamentação teórica que possibilite ações pedagógicas eficazes e potencializar a proximidade com o âmbito escolar, estimulando a construção coletiva de saberes e fazeres. Para aqueles profissionais que estão no desenvolvimento de suas atividades sugere-se o estímulo e o favorecimento para uma continuidade na formação, visando o aperfeiçoamento e a aquisição de novos conhecimentos (GOFFREDO, 1999; ARTIOLI, 2006; GLAT; PLETSCH, 2010; CARVALHO; ALMEIDA; SILVA, 2018).

No caso da formação específica para manejar o PDI, cabe ressaltar que a ferramenta funciona como um parâmetro que auxilia os docentes na prática e na elaboração de estratégias para alcançar a aprendizagem e o desenvolvimento do aluno. Os resultados explorados nesta pesquisa, conforme objetivo definido, foram direcionados para pontos do documento que podem ser aprimorados, fato que não exime a responsabilidade das instituições de ensino e dos atores envolvidos de assumirem um posicionamento de valorização da diversidade, de busca e promoção de capacitação e de conscientização do contexto escolar para uma verdadeira inclusão.

\section{O trabalho colaborativo e a utilização do instrumento PDI}

Diante do questionamento sobre quem realmente está preenchendo o PDI nas escolas estaduais de Minas e a opinião dos participantes sobre quem deveria preencher, foi apontado que há muitas pessoas atuantes nessa tarefa. Os professores demandam uma maior participação dos familiares do aluno, de outros profissionais que o acompanham (como intérpretes e aqueles que atuam na área da saúde) e dos professores do AEE no preenchimento do PDI.

O Gráfico 1 representa uma análise sobre a atuação colaborativa durante o preenchimento e construção do PDI. Responderam a esse questionamento 1.201 participantes. Os outros 53 não deram sequência no preenchimento do formulário por assinalarem não ter conhecimento sobre os itens do instrumento e encerraram a participação na pesquisa. 
http://dx.doi.org/10.5902/1984686X47967

A quase totalidade dos participantes (98\%) concordou que o processo de construção da ferramenta deve envolver todos os profissionais que participam da escolarização do aluno. Em contrapartida, 34\% dos respondentes afirmaram que, apesar dessa colaboração necessária, a articulação entre os profissionais da escola durante essa tarefa não se dá de forma satisfatória. Outros $64 \%$ afirmaram o contrário, que existe uma boa articulação entre os profissionais (Gráfico 1).

Gráfico 1 - Sobre a atuação colaborativa

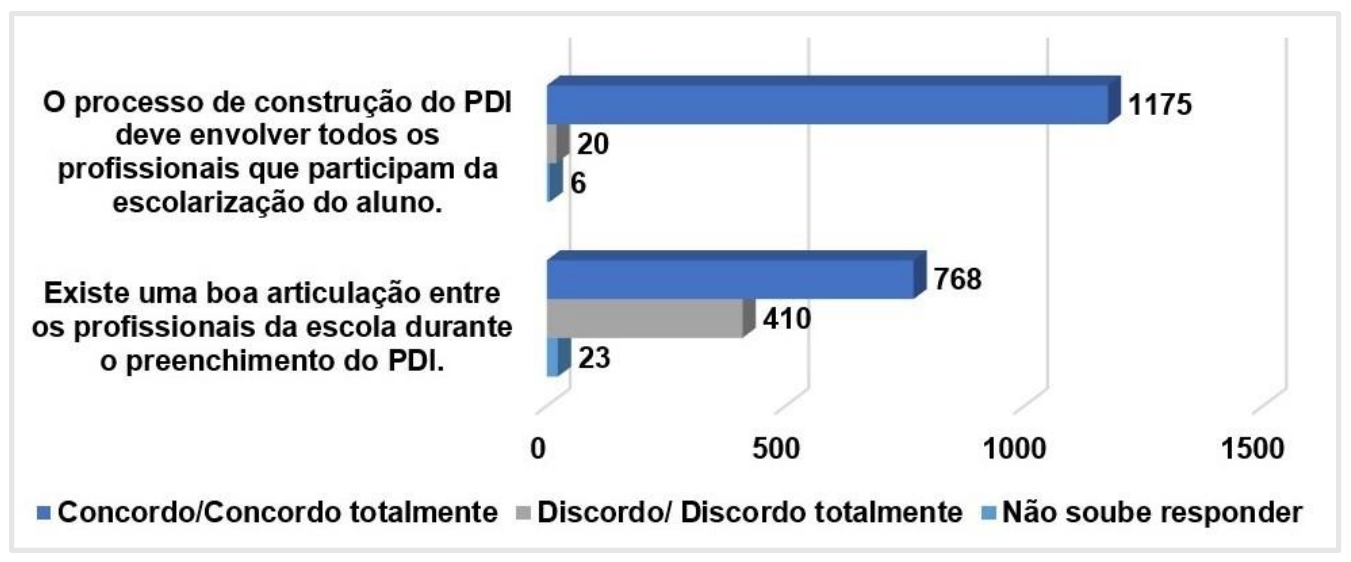

Fonte: Elaborado pelas autoras (2020).

Para Mello e Hostins (2019), a proposta do PEI deve ser pensada a partir do contexto em que o indivíduo está inserido e não deve ser elaborada de forma isolada. É importante que a construção do PEI seja de forma conjunta, envolvendo a participação de toda a equipe escolar e contribuindo para a materialização do trabalho entre os professores do ensino comum e especializado, permitindo uma fusão entre as práticas pedagógicas do ensino comum e da Educação Especial, cujo alvo é o mesmo aluno.

Quanto à verificação sobre a utilização do PDI nas escolas, foi evidenciado que os especialistas têm uma participação importante nessa tarefa. Conforme previsto nas orientações da SEE, esses profissionais articulam a comunicação entre os demais membros da equipe, exercendo papel de liderança e referência durante o processo de construção e revisão do documento. Os dados apontaram que os Diretores e a própria SRE também participam mais ativamente desse procedimento de fiscalização (Gráfico 2). 
http://dx.doi.org/10.5902/1984686X47967

Gráfico 2 - Quem verifica a utilização do PDI nas escolas?

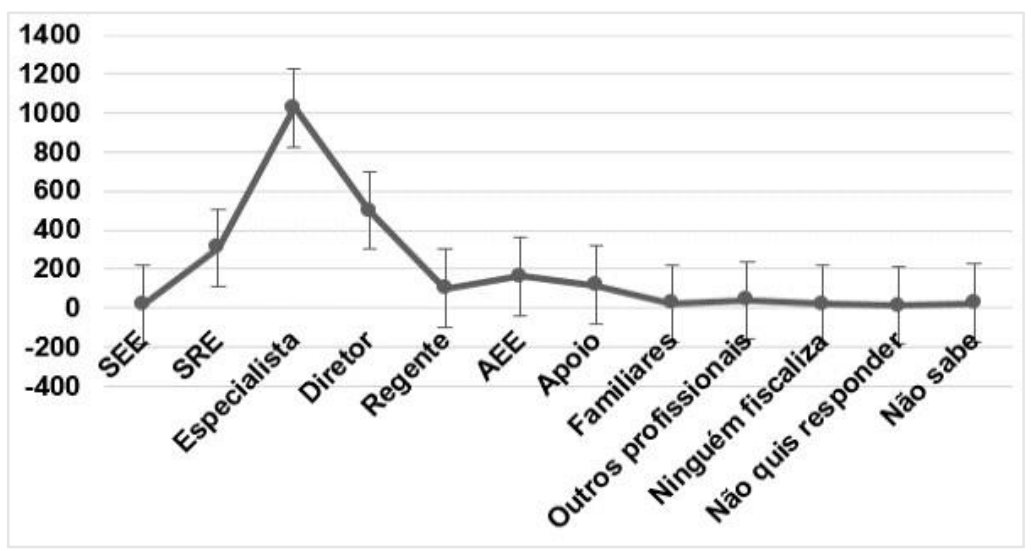

Fonte: Elaborado pelas autoras (2020).

Dentre os atores que apareceram com menos frequência, os familiares do aluno merecem destaque. A relação tem que ser de confiança e, dentre os papéis desempenhados pelos familiares para garantir uma boa inclusão, estão: participar ativamente na realização dos cadastros necessários; informar dados pertinentes; esclarecer quanto à rotina de atendimentos clínicos; enviar relatórios sobre o acompanhamento realizado na área de saúde; entregar laudos; relatar a história de vida, as limitações e os cuidados necessários do estudante; orientar sobre quais cuidados podem ser dispensados; participar de reuniões; acompanhar a vida escolar do aluno; garantir a frequência na escola e no AEE (MINAS GERAIS, 2016). Enfatiza-se que a família do aluno desempenha um papel importante junto à escola, pois possibilita a troca de informações sobre o estudante e o auxílio no desenvolvimento de estratégias bem direcionadas para as reais necessidades deles.

Sobre a afirmação: "a orientação do especialista é suficiente para conduzir o preenchimento do PDI", $61 \%$ dos participantes consideraram essa orientação insuficiente (Gráfico 3).

Gráfico 3 - Frase: "A orientação do especialista é suficiente para conduzir o preenchimento do PDI"

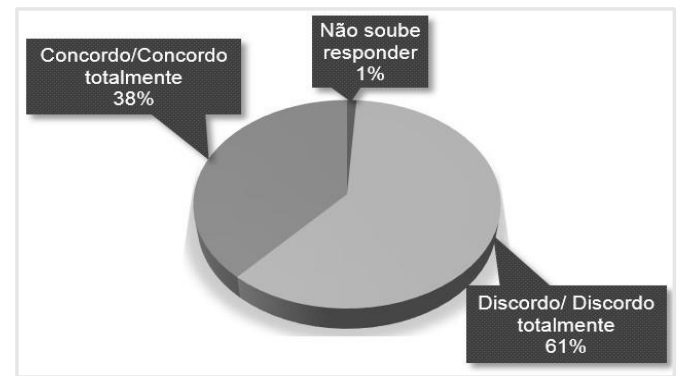

Fonte: Elaborado pelas autoras (2020). 
Interessante que, em $52 \%$ das respostas dos especialistas, estes assinalaram que não consideram as orientações dos próprios especialistas como suficientes. Esse dado chama a atenção e, apesar de esse profissional ter sido indicado como ator presente no processo de fiscalização, conforme Gráfico 2, ainda há uma dificuldade em orientar e conduzir o processo de utilização da ferramenta de forma satisfatória. O especialista pode não estar capacitado ou orientado sobre como executar essa tarefa.

Pereira (2014) afirma que há emergência na formação de pessoas capacitadas para a coordenação pedagógica, as quais possam articular e mediar as relações entre os diferentes profissionais da escola. Esse coordenador pode contribuir com a transformação e organização dos espaços escolares e na construção de práticas inclusivas a partir de reflexões compartilhadas. É preciso enfatizar que, em 38\% das respostas, houve a concordância de que a orientação do especialista tem sido suficiente, mas os resultados apontam que o sistema como um todo carece de maior aperfeiçoamento nessa função.

Sobre a opinião dos respondentes acerca da importância do PDI, com a possibilidade de assinalar mais de uma alternativa, $50 \%$ das respostas apontaram que a ferramenta é um instrumento excelente para facilitar o processo de inclusão do aluno. Já para $40 \%$ dos respondentes, houve o indicativo de que o Plano precisa ser aprimorado, pois é demorado de se preencher e, muitas vezes, os docentes não têm disponibilidade de tempo para um trabalho de preenchimento em equipe. Com menor incidência, $9 \%$ das respostas, houve aqueles que assinalaram não conseguir entender as orientações de preenchimento, apresentando dificuldades em associar os itens cobrados à realidade do aluno. Apenas $1 \%$ dos participantes afirmaram que o PDI não auxilia nas práticas pedagógicas e que é um documento desnecessário.

As opiniões apresentadas devem ser consideradas para possíveis aprimoramentos no documento, reorganização do sistema escolar para um preenchimento em equipe e capacitação dos docentes para atender as demandas apresentadas. Pletsch, Souza e Orleans (2017, p. 275) apontam que "faltam aos docentes conhecimentos teóricometodológicos que thes permitam compreender como o aluno aprende e o que o professor pode fazer para isso". Essa afirmação pode explicar os $9 \%$ de opiniões que indicam dificuldades frente às orientações do PDI e em identificar as potencialidades, as limitações e o desenvolvimento do estudante para definirem práticas pedagógicas direcionadas. 
Para a maioria dos participantes (90\%) que utilizam ou já utilizaram o PDI na rede estadual de educação, o instrumento é considerado útil ou muito útil durante o processo de inclusão do aluno da Educação Especial (Gráfico 4). Apesar de existir opiniões que indicam algumas dificuldades em utilizá-lo e a necessidade de capacitação, ele ainda é considerado um excelente instrumento para favorecer a inclusão.

Gráfico 4 - Utilidade do PDI

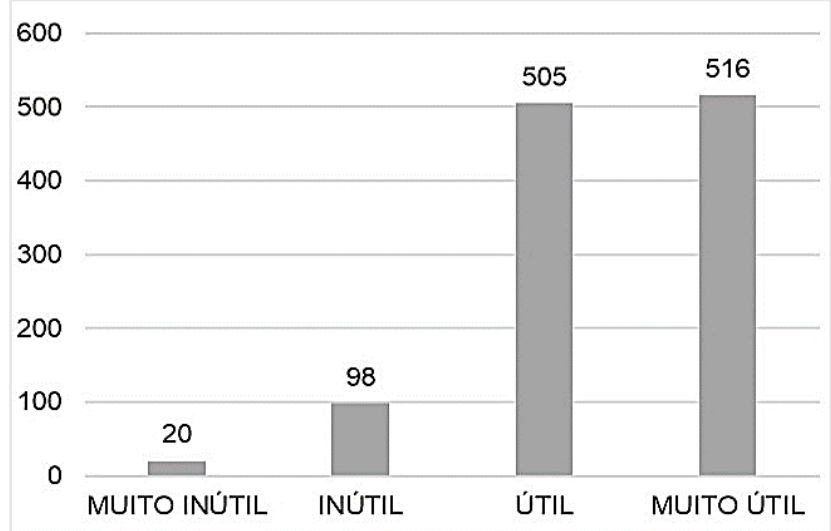

Fonte: Elaborado pelas autoras (2020).

Em outra questão, de 1.201 respostas, $84 \%$ dos respondentes concordaram com a assertiva de que o PDI norteia a atuação dos profissionais, indicando que o instrumento deve continuar sendo utilizado como recurso de inclusão. Foi perguntado, ainda, se o instrumento deveria ser informatizado como forma de facilitar o processo de registro; nesse sentido, $85 \%$ dos participantes assinalaram que essa seria uma boa opção. Sabe-se que, na prática, na maioria das escolas, o documento fica armazenado em arquivos manuais, fato este que pode dificultar o preenchimento do instrumento, a elaboração de análises e a sua consulta.

\section{Principais dificuldades apontadas nos itens do PDI}

As informações a seguir foram obtidas a partir da coleta de dados com o método de escala Likert, em que os sujeitos da pesquisa especificaram qual o nível de concordância ou dificuldade em determinada afirmação ou item. Para tanto, 1.201 respondentes foram direcionados, de acordo com suas respostas, para fazer uma avaliação sobre alguns aspectos que compõem o instrumento.

Em geral, os itens identificados como mais problemáticos durante o preenchimento do PDI se relacionam com a proposta curricular conforme o Projeto Político Pedagógico (PPP), 
http://dx.doi.org/10.5902/1984686X47967

a avaliação diagnóstica inicial do aluno, o planejamento pedagógico, a avalição processual e a correção de rumos. Tais componentes, quando mal elaborados, acarretam uma série de dificuldades nos outros itens avaliados. Essas informações permitem vislumbrar os itens do PDI que geram mais dúvidas e que necessitam de um treinamento mais específico para seu preenchimento.

De acordo com os dados, $49 \%$ dos respondentes afirmaram que sentem muita dificuldade ou dificuldade razoável durante o preenchimento do item III, descrito como proposta curricular prevista no PPP. Diretores, professores do AEE e especialistas assinalaram em maior número uma dificuldade razoável, já entre os professores de apoio e regentes, houve uma variação, prevalecendo pouca ou nenhuma dificuldade em $56 \%$ das respostas e muita dificuldade ou dificuldade razoável em $43 \%$ das respostas (TABELA 3).

Tabela 3 - Item III do PDI - proposta curricular prevista no PPP

\begin{tabular}{lcccccc}
\hline & $\begin{array}{c}\text { Muita } \\
\text { dificuldade }\end{array}$ & $\begin{array}{c}\text { Dificuldade } \\
\text { razoável }\end{array}$ & $\begin{array}{c}\text { Pouca } \\
\text { dificuldade }\end{array}$ & $\begin{array}{c}\text { Nenhuma } \\
\text { dificuldade }\end{array}$ & $\begin{array}{c}\text { Não sei } \\
\text { avaliar }\end{array}$ & Total \\
\hline Diretor & 53 & 181 & 161 & 83 & 4 & 482 \\
\hline Professor de apoio & 26 & 52 & 53 & 44 & 2 & 177 \\
\hline Professor do AEE & 18 & 50 & 35 & 27 & 2 & 132 \\
\hline Professor regente & 11 & 13 & 23 & 15 & 1 & 63 \\
\hline Especialista & 38 & 141 & 109 & 56 & 3 & 347 \\
\hline Total & $\mathbf{1 4 6}$ & $\mathbf{4 3 7}$ & $\mathbf{3 8 1}$ & $\mathbf{2 2 5}$ & $\mathbf{1 2}$ & $\mathbf{1 2 0 1}$ \\
\hline
\end{tabular}

Fonte: Elaborada pelas autoras (2020).

O PPP, bem como as matrizes curriculares e os conteúdos das matrizes devem ser consultados e anexados no PDI para subsidiar a construção do planejamento pedagógico e compor os registros do estudante. Salienta-se que o currículo é o mesmo contido na proposta curricular dos outros alunos e as adaptações devem ser realizadas na tentativa de atender às necessidades dos estudantes, na busca de um trabalho pedagógico que possibilite o seu desenvolvimento, a partir de suas capacidades (MINAS GERAIS, 2018).

A adaptação curricular não significa a exclusão do conteúdo de forma individual e aleatória, devendo ser orientada pelas discussões coletivas dos profissionais que participam do processo de ensino/aprendizagem do estudante, os quais embasados no PDI, definirão o que é indispensável para o pleno desenvolvimento do sujeito. A adaptação deve ser muito mais metodológica do que de conteúdo. Nesta perspectiva, buscar estratégias para que todos possam participar da aula é o que promove, de fato, a inclusão do estudante na turma (MINAS GERAIS, 2018, p. 7). 
Glat e Pletsch (2012) salientam que a escola deve incorporar o currículo no PPP, não apenas o conteúdo programático, mas também o planejamento, as metodologias, as estratégias de ensino, avaliações e demais aspectos. Coelho (2013, p. 146) afirma que "a construção de PEIs de cada aluno com necessidades educacionais articulada aos projetos curriculares da escola constitui um bom exemplo de uma experiência alinhada a uma filosofia inclusiva".

O resultado obtido permite o levantamento das seguintes questões: será que o problema está no PDI ou no Projeto Político Pedagógico? O currículo proposto pela escola permite um planejamento articulado? O currículo está estruturado para a diversidade do contexto escolar? Todas as questões citadas indicam que, em muitos casos, os problemas não são, exclusivamente, da Educação Especial, do aluno, ou do próprio PDI.

A tabela a seguir aponta que, em $60 \%$ das respostas, houve pouca ou nenhuma dificuldade quanto à avaliação diagnóstica inicial; porém, não menos significativo, 39\% dos dados asseguram que existe muita dificuldade ou dificuldade razoável nesse item (Tabela 4).

Tabela 4 - Item IV do PDI - avaliação diagnóstica inicial

\begin{tabular}{lcccccc}
\hline & $\begin{array}{c}\text { Muita } \\
\text { dificuldade }\end{array}$ & $\begin{array}{c}\text { Dificuldade } \\
\text { razoável }\end{array}$ & $\begin{array}{c}\text { Pouca } \\
\text { dificuldade }\end{array}$ & $\begin{array}{c}\text { Nenhuma } \\
\text { dificuldade }\end{array}$ & $\begin{array}{c}\text { Não sei } \\
\text { avaliar }\end{array}$ & Total \\
\hline Diretor & 50 & 163 & 167 & 96 & 6 & 482 \\
\hline Professor de apoio & 10 & 39 & 51 & 77 & 0 & 177 \\
\hline Professor do AEE & 12 & 31 & 49 & 40 & 0 & 132 \\
\hline Professor regente & 11 & 19 & 15 & 14 & 4 & 63 \\
\hline Especialista & 42 & 96 & 135 & 72 & 2 & 347 \\
\hline Total & $\mathbf{1 2 5}$ & $\mathbf{3 4 8}$ & $\mathbf{4 1 7}$ & $\mathbf{2 9 9}$ & $\mathbf{1 2}$ & $\mathbf{1 2 0 1}$ \\
\hline
\end{tabular}

Fonte: Elaborada pelas autoras (2020).

A avaliação diagnóstica inicial do estudante - item IV - abrange o levantamento de informações sobre a história de vida do estudante, especificando questões clínicas e diagnósticas, experiências escolares, incluindo a avaliação pedagógica inicial, aspectos do desenvolvimento e outros itens específicos. Esses dados deverão ser fornecidos por pessoas, relatórios ou outras escolas frequentadas pelo aluno (MINAS GERAIS, 2018).

Nessa discussão, cabe retomar o porquê da dificuldade analisada na Tabela 4, considerando que, no caso de um estudante em idade escolar inicial, a família será a principal fonte das informações, mas aquele aluno com trajetória escolar mais avançada, ao chegar em uma escola nova, poderá apresentar um PDI precedente elaborado em outras instituições de ensino, o que facilitará a identificação das necessidades educacionais. PDls anteriores poderão subsidiar os dados do item IV em questão, mas é necessário investigar 
se a dificuldade está na ausência de informações dos familiares e outros profissionais, se está relacionada à falta do documento, documentos mal elaborados ou se há dificuldade do professor em compreender os pontos avaliados nesse item.

Correia (1999), citado por Glat e Pletsch (2013), aponta a necessidade de uma anuência parental para aprovação do PEI. O ideal é que a família participe, em alguma medida, da elaboração do documento. No caso de jovens, os próprios alunos podem e devem ser consultados. Mello e Hostins (2019) também enfatizam que as expectativas e contribuições da família devem estar contempladas e que o PDI precisa acompanhar o percurso de escolarização do estudante.

Dentro do item IV também há uma avaliação pedagógica inicial. De posse das informações colhidas na avaliação diagnóstica inicial, o professor deve identificar as potencialidades do estudante, esclarecendo quais são as barreiras que já existem ou que podem surgir como interferência na aprendizagem e desenvolvimento global do aluno, bem como na definição das estratégias para responder às suas necessidades. Portanto, nesse item, são avaliados aspectos cognitivos, como memória, habilidades visuais, habilidades auditivas, percepção, atenção, raciocínio lógico, pensamento, linguagem, funções executivas; aspectos metacognitivos, como desenvolvimento motor e psicomotor; aspectos pessoais/interpessoais/afetivos, comunicação e avaliação das áreas de conhecimento (MINAS GERAIS, 2018).

Quando questionados sobre a realização da avaliação pedagógica inicial, 55\% dos participantes afirmaram que há pouca ou nenhuma dificuldade; já $44 \%$ relataram haver muita dificuldade ou uma dificuldade razoável (Tabela 5).

Os resultados apontam para a necessidade de rever esse item, além de indicarem a demanda por formações direcionadas que envolvam conhecimentos específicos sobre as funções mentais superiores e sobre a aprendizagem. Existem muitos itens a serem avaliados e é preciso pensar em formas mais eficientes de verificar a informação para que ela seja utilizada de maneira dinâmica em sala de aula. O professor poderá ter dificuldades em avaliar elementos como memória, cognição, funções executivas e todos os outros elencados. 
Tabela 5 - Item IV do PDI - avaliação pedagógica inicial

\begin{tabular}{lcccccc}
\hline & $\begin{array}{c}\text { Muita } \\
\text { dificuldade }\end{array}$ & $\begin{array}{c}\text { Dificuldade } \\
\text { razoável }\end{array}$ & $\begin{array}{c}\text { Pouca } \\
\text { dificuldade }\end{array}$ & $\begin{array}{c}\text { Nenhuma } \\
\text { dificuldade }\end{array}$ & $\begin{array}{c}\text { Não sei } \\
\text { avaliar }\end{array}$ & Total \\
\hline Diretor & 68 & 164 & 166 & 78 & 6 & 482 \\
\hline Professor de apoio & 18 & 36 & 62 & 61 & 0 & 177 \\
\hline Professor do AEE & 11 & 39 & 44 & 38 & 0 & 132 \\
\hline Professor regente & 12 & 17 & 21 & 10 & 3 & 63 \\
\hline Especialista & 47 & 112 & 120 & 64 & 4 & 347 \\
\hline Total & $\mathbf{1 5 6}$ & $\mathbf{3 6 8}$ & $\mathbf{4 1 3}$ & $\mathbf{2 5 1}$ & $\mathbf{1 3}$ & $\mathbf{1 2 0 1}$ \\
\hline
\end{tabular}

Fonte: Elaborada pelas autoras (2020).

Pletsch, Souza e Orleans (2017) ressaltam que os docentes não questionam a proposta da Educação Inclusiva, mas apresentam dificuldades na compreensão dos processos de aprendizagem de alunos com deficiência. O item IV está relacionado com a identificação do desenvolvimento do aluno, considerando dificuldades e potencialidades. Se existem problemas em executar o processo de avaliação inicial, consequentemente, não haverá a compreensão dos processos de aprendizagem, o que afetará todos os itens subsequentes no que concerne à definição de estratégias metodológicas, objetivos e recursos necessários.

O item VII visa à realização do planejamento pedagógico com foco no ato de planejar para agir. É necessário conhecer o currículo proposto para a turma e identificar o que é imprescindível para que o estudante PAEE possa acompanhar os pares, respeitando seu ritmo e suas possibilidades. É preciso analisar possíveis barreiras de aprendizagem e maneiras de superá-las, estabelecer estratégias metodológicas que assegurem a participação do aluno nas atividades da turma, definir prioridades, prazos e recursos (MINAS GERAIS, 2018).

Os resultados mostrados na Tabela 6 apontaram para $63 \%$ dos docentes com pouca ou nenhuma dificuldade e $36 \%$ com muita dificuldade ou dificuldade razoável em relação ao planejamento pedagógico.

Tabela 6 - Item VII do PDI - planejamento pedagógico (trimestral)

\begin{tabular}{lcccccc}
\hline & $\begin{array}{c}\text { Muita } \\
\text { dificuldade }\end{array}$ & $\begin{array}{c}\text { Dificuldad } \\
\text { e razoável }\end{array}$ & $\begin{array}{c}\text { Pouca } \\
\text { dificuldade }\end{array}$ & $\begin{array}{c}\text { Nenhuma } \\
\text { dificuldade }\end{array}$ & $\begin{array}{c}\text { Não sei } \\
\text { avaliar }\end{array}$ & Total \\
\hline Diretor & 40 & 154 & 173 & 111 & 4 & 482 \\
\hline Professor de apoio & 14 & 33 & 54 & 76 & 0 & 177 \\
\hline Professor do AEE & 6 & 30 & 43 & 53 & 0 & 132 \\
\hline Professor regente & 8 & 16 & 20 & 17 & 2 & 63 \\
\hline Especialista & 32 & 105 & 121 & 87 & 2 & 347 \\
\hline Total & $\mathbf{1 0 0}$ & $\mathbf{3 3 8}$ & $\mathbf{4 1 1}$ & $\mathbf{3 4 4}$ & $\mathbf{8}$ & $\mathbf{1 2 0 1}$ \\
\hline
\end{tabular}

Fonte: Elaborada pelas autoras (2020). 
O item VII também está diretamente relacionado com os itens anteriores. Se uma porcentagem dos docentes não consegue definir as necessidades educacionais dos estudantes, como vão definir as estratégias que melhor atendem às demandas de aprendizagem? Tannús-Valadão (2014, p. 154) destaca que, dentre as dificuldades encontradas no processo de construção dos PEls, "os profissionais pareciam demandar decisões e resultados rápidos e, muitas vezes, eles não dedicam muito tempo para uma análise mais minuciosa acerca da relevância dos objetivos de ensino, seleção das estratégias mais efetivas, etc".

A avaliação processual e correção de rumos, conforme item VIII, deve acontecer durante toda a implementação do planejamento. São necessárias atualizações de acordo com o desenvolvimento do estudante e adaptações para alcançar os objetivos estabelecidos. Uma reunião coletiva deverá ocorrer ao final de cada trimestre para atualização desse planejamento (MINAS GERAIS, 2018).

No item VIII, constatou-se que, em $37 \%$ das respostas, foi indicada muita dificuldade ou dificuldade razoável; já 62\% relataram haver pouca ou nenhuma dificuldade (Tabela 7).

Tabela 7: Item VIII do PDI - avaliação processual e correção de rumos

\begin{tabular}{lcccccc}
\hline & $\begin{array}{c}\text { Muita } \\
\text { dificuldade }\end{array}$ & $\begin{array}{c}\text { Dificuldad } \\
\text { e razoável }\end{array}$ & $\begin{array}{c}\text { Pouca } \\
\text { dificuldade }\end{array}$ & $\begin{array}{c}\text { Nenhuma } \\
\text { dificuldade }\end{array}$ & $\begin{array}{c}\text { Não sei } \\
\text { avaliar }\end{array}$ & Total \\
\hline Diretor & 50 & 149 & 183 & 93 & 7 & 482 \\
\hline Professor de apoio & 16 & 33 & 60 & 68 & 0 & 177 \\
\hline Professor do AEE & 8 & 32 & 47 & 45 & 0 & 132 \\
\hline Professor regente & 9 & 14 & 23 & 15 & 2 & 63 \\
\hline Especialista & 37 & 101 & 139 & 69 & 1 & 347 \\
\hline Total & $\mathbf{1 2 0}$ & $\mathbf{3 2 9}$ & $\mathbf{4 5 2}$ & $\mathbf{2 9 0}$ & $\mathbf{1 0}$ & $\mathbf{1 2 0 1}$ \\
\hline
\end{tabular}

Fonte: Elaborada pelas autoras (2020).

É importante salientar que o planejamento individual deve ser periodicamente avaliado e revisado. O estudante deve ser avaliado em seu "patamar atual de habilidades, conhecimentos e desenvolvimento, idade cronológica, nível de escolarização já alcançado e objetivos educacionais desejados em curto, médio e longo prazos" (GLAT; VIANNA; REDIG, 2012, p. 84). Essa revisão de objetivos e propostas elaboradas para o aluno carece de ser executada a partir do seu desenvolvimento, comparando ele com ele mesmo (CORREIA, 1999 apud GLAT; PLETSCH, 2013).

Informações analisadas em outra pergunta do questionário indicaram que $48 \%$ dos participantes executam uma revisão bimestral. Houve uma alteração recente nas orientações da SEE, determinando que a reavaliação do PDI deve ocorrer de forma 
http://dx.doi.org/10.5902/1984686X47967

bimestral, fato que justifica o dado obtido. Essa revisão permite realizar uma análise geral da situação de inclusão do aluno, rever os objetivos e metas estabelecidas e definir novos caminhos. Por outro lado, as opções revisão semestral, anual ou nunca apareceram em $49 \%$ das respostas, o que é preocupante.

O documento não está sendo revisado da forma como preveem as orientações da Secretaria. Parte dos docentes não realizam a reavaliação do documento, ignorando a orientação de um período estabelecido, por motivos ainda desconhecidos. Essa questão precisa ser reforçada com os profissionais, pois o PDI necessita, em sua concepção, de uma reavaliação constante. Se essa reavaliação não é feita, o instrumento perde totalmente seu valor.

\section{Considerações finais}

Esse artigo teve como objetivo apresentar a percepção dos profissionais da educação sobre o PDI instituído pela Secretaria Estadual de Educação de Minas Gerais. A análise dos questionários demonstrou uma baixa adesão dos professores regentes à pesquisa. Os aspectos relacionados à formação dos professores para atuarem junto ao PAEE também chamaram a atenção. Uma quantidade considerável de respondentes $(39,1 \%)$ disse não ter recebido formação para atuar junto aos alunos.

Quanto às instruções específicas para utilizar o PDI, os dados oscilaram entre as regionais, sendo que nenhuma delas capacitou a totalidade dos profissionais respondentes. Outro dado relevante da pesquisa foi a identificação da importância do especialista na rede de educação analisada. Esse profissional mostrou-se uma figura chave na mediação entre os professores regente, de apoio e da Sala de Recursos. Sua função não se limita à escola, devendo articular com a família e com os profissionais externos a participação destes na escrita do PDI.

A articulação com a família mostrou-se falha, evidenciando a necessidade de fortalecimento dessa parceria para a educação dos alunos PAEE. Metade dos respondentes consideraram o PDI um instrumento importante, enquanto outra parcela significativa indicou que o recurso necessita ser aprimorado. Do total de respondentes, 84\% apontou que o PDI é um recurso que auxilia no processo de inclusão dos alunos da Educação Especial.

As dificuldades dos profissionais foram evidenciadas nas questões relacionadas à articulação do PDI com o Projeto Político Pedagógico da escola e em relação às avaliações. 
Quanto ao PPP, a preocupação é que o PDI não fique deslocado das matrizes curriculares e que realmente faça parte da rotina da escola, independentemente de ser uma obrigatoriedade. Quanto às avaliações diagnóstica e pedagógica iniciais, as dificuldades remetem à falta de capacitação para a atuação junto ao PAEE.

É importante destacar que uma das limitações do estudo foi a impossibilidade de cruzar as respostas obtidas através do questionário com a análise de Planos de Desenvolvimento Individual preenchidos por amostras de professores de todas regionais. Esse cruzamento possibilitaria apontar possíveis incongruências nas respostas.

De qualquer forma, é possível considerar o PDI como um recurso que auxilie o professor na definição de percursos educacionais que sejam relevantes para os alunos com deficiência. Os ajustes curriculares carecem de discussões coletivas que envolvam os diversos profissionais da escola que participam desse processo de ensino/aprendizagem. Devem envolver, ainda, familiares e outros profissionais que atuam com os estudantes fora do ambiente escolar. É necessário insistir na importância do trabalho colaborativo nas escolas, integrando os professores em torno do aluno, sem esquecer da contribuição da família, que costuma ser muito negligenciada, como visto na pesquisa. O PDI é um instrumento que pode auxiliar o professor, mas é necessário um conhecimento sobre o aluno e sobre o processo de inclusão para que ele seja, de fato, eficiente.

\section{Referências}

ARTIOLI, Ana Lúcia. A educação do aluno com deficiência na classe comum: a visão do professor. Psicologia da Educação, São Paulo, 23, p. 103-121, 2006.

BABBIE, Earl. Métodos de pesquisa de survey. 2 ed. Belo Horizonte: UFMG, 2003.

CARVALHO, Damila Soares; ALMEIDA, Mariângela Lima; SILVA, Nazareth Vidal. Formação continuada na perspectiva da inclusão escolar: desafios e possibilidades.

Perspectivas em Dialogo: Revista de Educação e Sociedade, Naviraí, v. 5, n. 9, p. 1936, 2018. ISSN 2358-1840.

COELHO, Cristina Lúcia Maia. Cenas da inclusão: modelos e intervenções em experiências portuguesa e brasileira. Revista Brasileira Estudos Pedagogia. Brasília, v. 94, n. 236, p. 125-149, 2013.

GLAT, Rosana; PLETSCH, Márcia Denise. O papel da Universidade no contexto da política de Educação Inclusiva: reflexões sobre a formação de recursos humanos e a produção de conhecimento. Revista Educação Especial, Santa Maria, v. 23, n. 38, p. 345-356, 2010. 
GLAT, Rosana; PLETSCH, Márcia Denise. A escolarização de alunos com deficiência intelectual: uma análise da aplicação do Plano de Desenvolvimento Educacional Individualizado. Linhas críticas, Brasília, DF. V.18, n.35, p. 193-208, 2012. ISSN 15164896.

GLAT, Rosana; VIANNA, Márcia Marin; REDIG, Annie Gomes. Plano Educacional Individualizado: uma estratégia a ser construída no processo de formação docente. Ciências Humanas e Sociais em Revista, RJ, EDUR, v. 34, n. 12, p. 79-100, 2012.

GLAT, Rosana; PLETSCH, Márcia Denise. Plano Educacional Individualizado: um diálogo entre práticas curriculares e processos de avaliação escolar. In: GLAT, R.; PLETSCH, M. D. (Orgs.). Estratégias educacionais diferenciadas para alunos com necessidades especiais. Rio de Janeiro: EdUERJ, p. 17-32, 2013.

GOFFREDO, Vera Lúcia Flor Sénéchal. Como formar professores para uma escola inclusiva? In: Ministério da Educação. Salto para o futuro Educação especial: tendências atuais. Brasília, 1999.

INSTITUTO NACIONAL DE ESTUDOS E PESQUISAS EDUCACIONAIS ANÍSIO TEIXEIRA (INEP). Sinopses Estatísticas da educação básica, 2019. Brasília: Inep, 2019. Disponível em: http://portal.inep.gov.br/sinopses-estatisticas-da-educacao-basica. Acesso em: 29 jun. 2020.

MELLO, Alessandra de Fátima Giacomet; HOSTINS, Regina Célia Linhares. Plano Educacional Individualizado: a colaboração docente como processo, a aprendizagem e a inclusão escolar como propósito. In: LUNARDI-MENDES, G. M.; PLETSCH, M. D.; HOSTINS, R. C. L. Educação especial e/na educação básica: entre especificidades e indissociabilidades [recurso eletrônico] - 1. ed. - Araraquara [SP]: Junqueira \& Marin, 2019. Disponível em: https://anped.org.br/sites/default/files/images/ebook-educacaoespecial-e-na-educacao-basica.pdf. Acesso em: 29 jun. 2020.

OLIVEIRA, Eloiza; MACHADO, Kátia da Silva. Adaptações curriculares: caminho para uma educação inclusiva. In: GLAT, R. Educação Inclusiva: cultura e cotidiano escolar. 2 ed. Rio de Janeiro: 7Letras, 2013.

PEREIRA, Débora Mara. Análise dos efeitos de um Plano Educacional Individualizado no desenvolvimento acadêmico e funcional de um aluno com transtorno do espectro do autismo. 2014. Dissertação (Mestrado em Educação) Universidade Federal do Rio Grande do Norte, Rio Grande do Norte, 2014.

PLETSCH, Márcia Denise; SOUZA, Flávia Faissal; ORLEANS, Luis Fernando. A diferenciação curricular e o desenho universal na aprendizagem como princípios para a inclusão escolar. Revista Educação e Cultura Contemporânea, v. 14, n. 35, Rio de janeiro, p. 264-281, 2017.

REDIG, Annie Gomes; MASCARO, Cristina Angélica Aquino de Carvalho; DUTRA, Flávia Barbosa da Silva. A formação continuada do professor para a inclusão e o plano educacional individualizado: uma estratégia formativa? Revista Diálogos e Perspectivas em Educação Especial, Edição Especial, v. 4, n. 1, p. 33-44, 2017 
SIQUEIRA, Carla Fernanda de Oliveira. et al. Planos de Ensino Individualizados na escolarização de alunos com deficiência intelectual. In: V Congresso Brasileiro de Educação Especial. Londrina de 05 a 07 de novembro de 2013, p. 3281- 3289.

TANNÚS-VALADÃO, Gabriela. Inclusão escolar e Planejamento Educacional Individualizado: avaliação de um programa de formação continuada para educadores. 2014. Tese (Doutorado) - Universidade Federal de São Carlos, São Paulo, 2014.

TANNÚS-VALADÃO, Gabriela; MENDES, Enicéia Gonçalves. Inclusão escolar e o Planejamento educacional individualizado: estudo comparativo sobre práticas de planejamento em diferentes países. Universidade Federal de São Carlos, São Carlos, SP, Brasil. Revista Brasileira de Educação, v. 23, 2018.

VIANNA, Márcia Marin; SILVA, Suzanli Etef; SIQUEIRA; Carla Fernanda de Oliveira. Plano Educacional Individualizado- que ferramenta é esta? In: VII Encontro da Associação Brasileira de Pesquisadores em Educação Especial. Londrina de 08 a 10 de novembro de 2011, p. 2824- 2835.

\section{Fontes documentais}

BRASIL. Lei Federal n 9.394 de 1996. Lei de Diretrizes e Bases da Educação. Brasília, DF, 1996.

BRASIL. Ministério da educação. Secretaria de Educação Especial. Parâmetros curriculares Nacionais. Adaptações curriculares. Estratégias para a educação de alunos com necessidades educacionais especiais / coordenação geral: SEESP/MEC. ARANHA, M. S. F. (Org.). Brasília, DF, 1998.

BRASIL. Ministério da educação. Projeto Escola Viva, Garantindo o Acesso e Permanência de Todos os Alunos na Escola. Alunos com necessidades educacionais especiais. Adaptações curriculares de grande porte. Brasília, DF, 2000.

BRASIL. Resolução CNE/CEB no 2, de 11 de setembro de 2001. Institui Diretrizes Nacionais para a Educação Especial na Educação Básica. Brasília, DF, 2001.

BRASIL. Ministério da Educação. Secretaria de Educação Especial. Estratégias para a educação de alunos com necessidades educacionais especiais. (Saberes e práticas da inclusão). Brasília, DF, 2003.

BRASIL. Ministério da Educação. Secretaria de Educação Especial. Política nacional de educação especial na perspectiva da educação inclusiva. Brasília, DF, 2008.

BRASIL. Lei Federal no 13.146 de 2015. Lei Brasileira de Inclusão da Pessoa com Deficiência. Estatuto da Pessoa com Deficiência. Brasília, DF, 2015.

MINAS GERAIS. Secretaria de Estado de Educação. Caderno de textos para formação de professores da rede pública de ensino de Minas Gerais. Minas Gerais, BH, 2006. 
MINAS GERAIS. Secretaria de Estado de Educação. Guia de Orientação da Educação Especial na rede estadual de ensino de Minas Gerais. Versão 3. Minas Gerais, BH, 2014.

MINAS GERAIS. Secretaria de Estado de Educação. Cartilha para pais, estudantes e profissionais da educação. A educação especial na perspectiva inclusiva. Minas Gerais, $\mathrm{BH}, 2016$.

MINAS GERAIS. Secretaria de Estado de Educação. PDI- Plano de Desenvolvimento Individual do Estudante. Minas Gerais, BH, 2018.

\section{Notas}

1 Individualized Educational Plan (IEP) - Estados Unidos; Projet Educatif Individualisé (PEI) - França; Programa Educativo Individual (PEI) - Portugal; Piano Educativo Personalizzato (PEP) - Itália; Individuell Utbildningsplan (IU) Sueco; Individueller Bildungsplan (IU) Alemanha.

2 Hoje Coordenação da Educação Especial Inclusiva.

\section{Correspondência}

Bruna Cristina da Silva Hudson - Universidade Federal de Minas Gerais, Av. Pres. Antônio Carlos, 6627, Pampulha, Belo Horizonte, Minas Gerais - Brasil.

CEP: $31270-901$

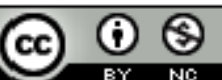

4.0 International (CC BY-NC 4.0) 